\section{Box 2: Medals forfeited during the Summer Olympic Games}

By country and sport, the number of medalsforfeited as a consequence of drug testing at Olympic Games since 1968, when the International Olympic Committee began testing athletes for banned substances. The lists do not include medals that were subsequently revoked, like the 3 gold and 2 bronze that were recently stripped from disgraced US sprinter Marion Jones after she admitted in court that sheíd been a persistent abuser of performanceenhancing drugs.

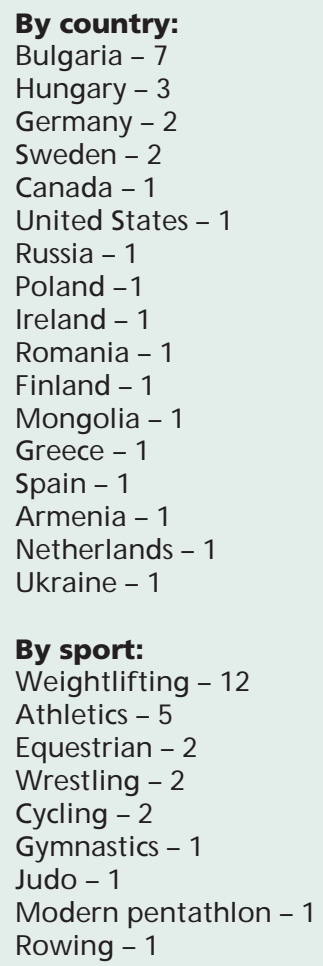

Neither of the groups has yet surfaced amongst athletes in competition testing. But the World Anti-Doping Agency added them to the list in a proactive move.

Authorities also say they are on particularly high alert because the Games are being held in Beijing. Many black market drugs originate from China and having the athletes in such close proximity to manufacturers risks making the drugs more readily available.

"There have been concerns in China," Howman says. "The greater concern is because that's where [black market drugs] come from."

It all seems a monumental task for an agency whose headquarters in Montréal does not match the image of a highly sophisticated lab where scientists work around the clock in the struggle to stay a step ahead of dopers. Rather, it is a simple office, where the agency coordinates various sporting bodies and governments and their policies on drugs.

About 50 staff work in the Montréal office, forming the bulk of the 60 people employed worldwide by the agency, which has smaller offices in Switzerland, Uruguay, South Africa and Japan.

"We have scientists, lawyers, antidoping protocol specialists and communications experts," says agency spokesman Frédéric Donzé, adding that about 15 nationalities are represented amongst the Montréal staff. "We have a very broad background."

Their work has expanded greatly since 1999, and their 2008 budget of US\$26.5 million is more than triple what they had to spend in their first year - a sign that as more and more individual sporting federations take on the responsibility of direct drug testing, there is much work to be done in coordinating and reviewing policies.

As well, there's the constant watch for new doping practices and inventive uses of everyday products. As past Olympics have proven, the Games are where previously unheard-of tactics surface.

Beijing will doubtless prove no exception. - Christopher Mason, Ottawa, Ont.

DOI:10.1503/cmaj.080993

\title{
Medical Team Canada: bouncing to Beijing in aid of the medal haul
}

$\mathrm{W}$ hen Canadian athletes arrive in Beijing to compete in the upcoming Summer Olympics, it will not necessarily be pulled hamstrings, broken bones or other traditional ailments that keep Team Canada's medical staff up at night.

Instead, their biggest challenge will be preparing elite athletes to perform in a steamy, smog-filled climate that could severely affect the respiratory and cardiovascular health of team members. That's because all the healthy hamstrings and strong muscles in the world will be of little use if an athlete is left unable to breathe comfortably.

In fact, concerns over air quality in Beijing have so worried Olympic officials that the International Olympic Committee ruled asthmatic athletes will be permitted to use inhalers in Beijing, under the therapeutic-use exemption.

\section{Box 1: Medical Team Canada}

The Canadian Olympic Committee says 41 medical staff will be dispatched to Beijing to support athletes as they vie for medals at the Games of the XXIX Olympiad. Those include 10 physicians, hailing from across the country, as follows:

Chief Medical Officer Dr. Robert McCormack (New Westminster, BC)

Assistant Chief Medical Officer Connie Lebrun (Edmonton, Alta.)

Dr. Alan Vernac (Montréal, Que.)

Dr. Julia Alleyne (Toronto, Ont.)

Dr. Mike Wilkinson (Vancouver, BC)

Dr. Teresa Lynn DeFreitas (Edmonton, Alta.)

Dr. Victor Lun (Calgary, Alta.)

Dr. Renata Frankovish (Ottawa, Ont.)

Dr. Andrew Pipe (Ottawa, Ont.)

Dr. Andrew Marshall (Ottawa, Ont.) 
On his first trip to Beijing as Team Canada's Chief Medical Officer for this summer's games, Dr. Robert McCormack, noticed that air quality ratings that would cause stay-home warnings in smoggy Toronto were considered "good days" in Beijing.

"I used to compete in track and field so I run a lot," McCormack says. "I got over there and I couldn't run because the air was just horrible."

McCormack and his Team Canada medical staff may fly under the radar in terms of public recognition. But they are key to Canada's hopes of performing well in Beijing, especially as the ability to mitigate health hazards is doubly important given the conditions.

"Air quality in China and concerns about food and water quality in a country that is essentially still a developing country have been our biggest concern," McCormack says.

In the weeks, months and even years leading up to the Beijing Olympics, Canada's medical team has busied itself to have everything in place so that the athletes can focus on winning medals with as few medical distractions as possible.

McCormack has been to Beijing 4 times to line up the necessary supplies and facilities, build relationships with local officials and better understand the setting so doctors will have a wellformed idea of what to expect when the athletes arrive.

"We need to be over there so that when we arrive for the Games we can hit the ground running," he says.

Supplies and equipment were sent over months in advance and McCormack and others have been arranging local officials who can help Canadian staffers get other supplies on short notice, once the Olympics get underway.

Besides taking precautions on food and water, there is little that can be done about air quality, though McCormack notes that on his most recent visit he was impressed by efforts to establish more green space in the city and reduce the emissions, if only temporarily, at factories in the region.

In the past Team Canada's medical staff focused on reactionary care, treating any injuries that surfaced during the Olympics. But now that role has evolved

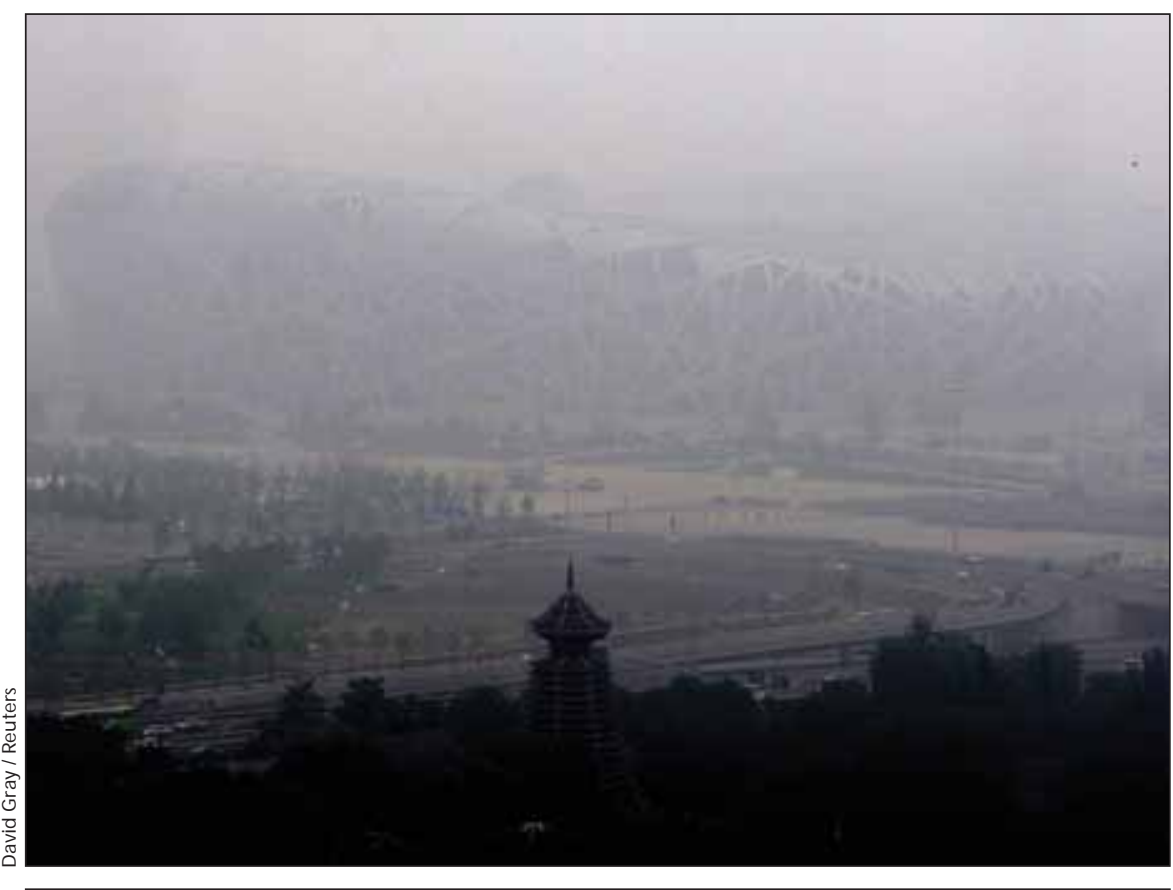

Smog often envelops the "Bird's Nest," the national stadium in which the opening ceremonies of the 2008 Beijing Olympics will be held. At least 1 nation, Australia, has ordered some of its team members to stay away from the ceremonies because of fears that the pollution will harm performance. Australia also launched a major immunization program to protect athletes from infectious diseases and respiratory problems associated with pollution. Canada has not followed suit, although Team Canada Chief Medical Officer Dr. Robert McCormack acknowledges concerns about air quality.

and the 10 doctors (Box 1) and 41 total team members (including therapists) who will be in Beijing have been involved much earlier in advising athletes how to prepare themselves for the Olympics. "Before, we were 'care and comfort', so that if someone got hurt we would care for them to get them in shape to compete, if possible," McCormack says.

"Today, we still have to do that. But we work a lot on performance enhancement before the Games to make sure our athletes are prepared with the best sports science, the best nutrition and are prepared to deal with potentially bad air."

In addition, medical staffers are thoroughly prepped on the rules and regulations of the World Anti-Doping Agency and the International Organizing Committee so that if Beijing pollution affects any of the Canadian athletes, they can be treated without breaking any doping rules.

Each country is tasked with setting up its own medical facilities, though there is a central clinic established by the host country in the Olympic Village to provide advanced care, as well as serve those countries that simply cannot afford their own medical staff and supplies.

In the case of a life-threatening or very serious injury, the host country takes over. "But in most cases, our doctors will handle the injury, bring the athlete back to the medical village and arrange whatever tests we need," McCormack says.

The host country provides advanced care like magnetic resonance imaging and computed tomography scans, as well as access to hospitals and dentists for serious care or surgical requirements. But Team Canada's medical team brings its own medicine and basic treatment and therapy supplies.

Because of the added medical responsibility that comes with hosting the Olympics, many of Canada's medical staff are also undertaking what is essentially a trial run for the 2010 Winter Olympics to be held in Vancouver, British Columbia. It has already been confirmed that McCormack will be the 


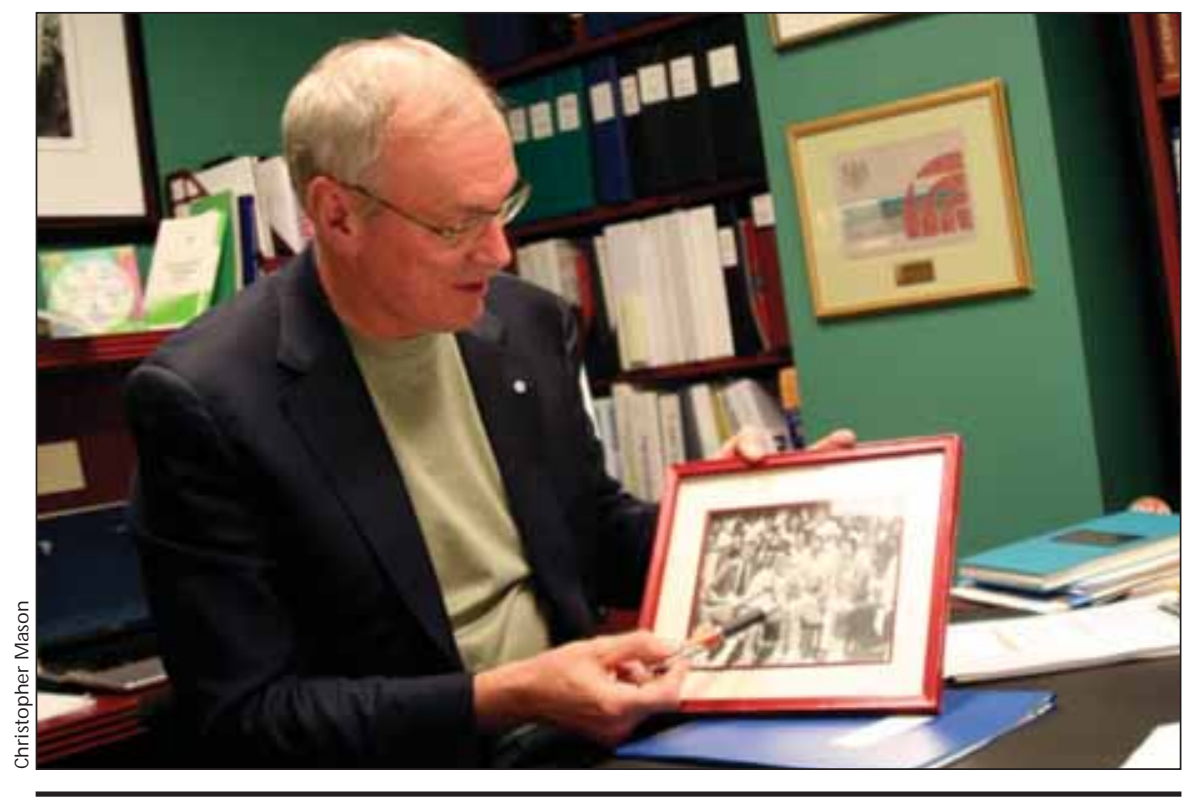

Dr. Robert McCormack is Team Canada's chief medical officer at the Beijing Olympics. The New Westminster, BC, physician has been to China 4 times to line up supplies and facilities that will be needed by the 41 medical staff who'll venture to the Games in support of Canadian athletes.

chief medical officer for those games.

Typically, most individual teams have their own doctors and therapists and would prefer them to accompany the teams to Beijing. But as there isn't enough space or resources to send each team's medical staff to the Games, the Canadian Olympic Committee, along with the chief medical officer and the assistant chief medical officer, selected the staff, reviewing applicants for multisport familiarity, among other factors.

A doctor with experience treating, say, basketball players as well as boxers and wrestlers has a better shot of being chosen to Canada's medical team as that physician can knowledgeably serve more than one team. Officials also look for a balance between experienced doctors and younger ones who will be able to serve in future events.

For medical staff venturing to Beijing, the work is less a shot at glamour and more a labour of love: the hours are long, the stress high and the pay, well, all but non-existent.

Many medical staff in elite-level amateur sport typically bank their vacation time or go on unpaid leave from their jobs to accommodate their commitments. In recounting his Olympic experiences, Dr. Andrew Pipe remembers having time in 1992 to watch the first half of a basketball game and some swimming events.

But otherwise, the bulk of his time was mostly spent in clinics serving athletes who needed treatment - fast.

"Many people have this idea that it's great and they ask if my wife will come so we can do some touring and I say 'well, no'," says Pipe, who was Canada's chief medical officer at the 1992 Olympics and is on the Beijing team. "You're sleeping 2 to a room, up at 6 am and back at maybe 1 or 2 am - it is not as glamorous as it may sound."

The landscape has changed a lot since Pipe first became involved in Olympics medicine over 30 years ago. At the time, Sudbury, Ont. had a stateof-the-art track that drew elite tournaments. Pipe had a practice in a nearby community, and began treating athletes at the track. That led to more and more work, and eventually a spot on the 1976 Olympic medical team. He has gone on to specialize in basketball, having been a doctor for the Canadian men's basketball team since the late 70 s.

Similarly, McCormack started locally, working with athletes at Simon Fraser University in Burnaby, BC. He then did provincial competitions, the
Pan-American Games and eventually, became chief medical officer at a Commonwealth Games before joining Team Canada at the 2000 Sydney Olympics.

"Start locally, build up to the provincial level and go from there," McCormack says by way of advice to young doctors seeking to become a member of Medical Team Canada. "You're not going to get selected to go to the Olympics if you haven't built up the experience and worked at multisport events. It's like applying to medical school: you have to get the marks but you also have to do the things that make you an attractive candidate."

The pride and memories that come from the years dedicated to treating Olympians are evident in the stories that emerge in discussing past events. For McCormack, it is in one breath talking about the logistical challenges of establishing a medical operation in Beijing and in the next, talking about the feeling one gets having a rink-side seat to a hockey game featuring the world's best players.

For Pipe, it is revealed in the photos that surround him in his office at the Ottawa Heart Institute where he is medical director of the Minto Prevention and Rehabilitation Centre. In one, he and several athletes stand on the Great Wall of China. In another, he is pictured with Team Canada and the US men's basketball Dream Team of the early 1990s. A third commemorates Canada's 1983 defeat of Yugoslavia in the final of the World University Games, after Canada had upset a US team featuring Charles Barkley and Karl Malone in the semifinals.

"I have been blessed with an opportunity to see the world from a perspective not available to the typical traveller," he says.

The memories are solace for the years of dedication and time spent away from home and understanding families.

"You have to have endurance to put in the time and you have to be committed," McCormack says. "Perhaps committed in more ways than one. Sometimes my wife thinks I should be committed [medically speaking]." Christopher Mason, Ottawa, Ont.

DOI:10.1503/cmaj.080985 